\title{
"I couldn't have seen it coming": The impact of negative self-relevant outcomes on retrospections about foreseeability
}

\author{
Melvin M. Mark \\ Pennsylvania State University, USA \\ Renee Reiter Boburka \\ East Stroudsburg University, PA, USA \\ Kristen M. Eyssell \\ Gettysburg College, PA, USA \\ Laurie L. Cohen \\ Arizona State University, USA \\ Steven Mellor \\ University of Connecticut, USA
}

\begin{abstract}
We examined a phenomenon related to hindsight bias, specifically, retrospective judgements about the foreseeability of an outcome. We predicted that negative, self-relevant outcomes would be judged as less foreseeable by the recipient of the outcome than by others, unlike either positive outcomes or outcomes that are not self-relevant. In the context of a "stock market decision-making game", the hypothetical stock selected by one of two players showed an extreme increase or decrease. As predicted, the player who received an extreme negative outcome reported that this outcome was less foreseeable than did the opponent and an observer, for whom the outcome was less self-relevant. For no other kind of outcome was there a difference between the recipient of an outcome, the opponent, and the observer. The findings have several implications, including the possibility that hindsight bias should be considered as a special case of retrospective foreseeability.
\end{abstract}

Hindsight bias refers to the tendency, once the outcome of a particular event is known, to overestimate how predictable that outcome was in foresight. Hindsight bias has been demonstrated in a variety of applied and experimental settings (see Hawkins \& Hastie, 1990, and ChristensenSzalanski \& Willham, 1991, for reviews). Fischhoff (1975), in his seminal work in this area, suggested that hindsight bias makes it difficult to learn the lessons of the past. Many authors have since echoed this argument (e.g., Christensen-Szalanski \& Willham, 1991; Fischhoff, 1982). For example, Arkes and his colleagues (Arkes, Faust, Guilmette, \& Hart, 1988; Arkes, Wortmann, Saville, \& Harkness, 1981) note that if, after learning about a confirmed diagnosis a physician believes that he

Requests for reprints should be sent to Melvin M. Mark, Department of Psychology, 417 Moore, Penn State University, University Park, PA 16802, USA. Email: M5M@PSU.EDU

Thanks are due to three anonymous reviewers and the Special Issue editors for helpful feedback on previous drafts. 
or she "knew-it-all-along", the outcome information may not provide the learning that might otherwise take place. In contrast to this original focus on its negative impact on decision making, in recent years hindsight bias has been framed as a natural byproduct of generally functional processes. "Adjusting conclusions in light of outcome information is the sine qua non of learning, but carries the attendant effect of an exaggerated certainty regarding that outcome. As such, the hindsight bias is best viewed on the same conceptual field as other functionally sound cognitive simplifications, such as attitudes, stereotypes, and impressions: Quick and often pragmatically useful inferences that are sometimes made at the expense of accuracy" (Roese \& Olson, 1996, p. 224; also see Hoffrage, Hertwig, \& Gigerenzer, 2000, p. 579).

This re-framing of the hindsight bias has three important implications that underlie the present research. First, hindsight bias should not be seen as a singular, distinct phenomenon, but should be considered in the context of related psychological processes. Second, expanding on Roese and Olson's analysis, receipt of outcome information sometimes leads to the development rather than to the adjustment of conclusions. Outcomes often arise about which people have not made prior judgements of likelihood (unless prompted to by a researcher's question, as in a hindsight bias study). Few people, for instance, probably estimated in foresight the likelihood that the estranged wives of O.J. Simpson and Robert Blake would be murdered. Of course, although many events such as these occur about which people have not made prior likelihood judgements, certain other events, such as highly publicised trials, sporting events, and elections, may readily stimulate judgements in foresight about the likelihood of the alternative outcomes. However, even when people are faced with processes that could easily elicit prospective judgements of likelihood, they are sometimes, by virtue of their roles, admonished to suspend judgements about what the outcome will be. For instance, jurors are often instructed to suspend judgement until all the evidence has been presented.

The literature on hindsight bias can be seen as a special but important case in which individuals make retrospective judgements of foreseeability. In essence, research on hindsight bias attempts to compare the retrospective foreseeability judgements of those with outcome information to either (1) judgements of those same individuals prior to receiving outcome information (within-subject designs) or (2) judgements of other individuals with no outcome information (between-subjects designs) (Schwarz \& Stahlberg, 2003-this issue). Yet comparison to a no-outcome-knowledge condition is not intrinsically required for the study of retrospective foreseeability judgements. Indeed, related literatures, such as work on counterfactual thinking, have progressed well without always including a no-outcome-information control (e.g., Markman \& Tetlock, 2000; Sherman \& McConnell, 1995). Moreover, without broader attention to retrospective foreseeability judgements in general, research on hindsight bias alone may leave several important questions unanswered. For instance, it is not clear whether the findings of hindsight bias studies apply equally well to cases in which likelihood judgements would, and would not, be made spontaneously in foresight without the researcher's probing. In addition, hindsight bias designs focus attention on the outcome information-no outcome information contrast. This may in a sense serve as a heuristic for researchers, drawing attention away from investigation of related questions involving retrospections about foreseeability.

Recent re-framing of the hindsight bias also has a third implication. By pointing out the similarity of hindsight bias to other "functionally sound cognitive simplifications", Roese and Olson indirectly highlight the possible role of certain motivational factors in retrospective judgements of foreseeability. In particular, the impact of selfprotective and self-enhancing mechanisms have been demonstrated in several other areas where "cognitive simplifications" provide quick, often useful inferences (e.g., Brown, 1986; Dunning, Leuenberger, \& Sherman, 1995; Greenwald, 1980; Kunda, 1987; Taylor \& Brown, 1988; Wood, Taylor, \& Lichtman, 1985). In fact, self-protective mechanisms have received some attention in the hindsight literature. Mark and Mellor (1991) examined whether the self-relevance of a negative outcome moderates the magnitude of hindsight. Laid-off union members, survivors (i.e., union members who were not laid off), and non-union community members made retrospective judgements of the foreseeability of the layoff. The layoff should have been most self-relevant for the laid-off group, somewhat self-relevant for the layoff survivors, and low in self-relevance for the community members. As predicted, laid-off respondents reported less foreseeability than layoff survivors, who in turn reported less foresee- 
ability than community members. These results were strengthened by the use of the regressiondiscontinuity design (Cook \& Campbell, 1979). Workers were laid off according to seniority, and analyses indicated there was a discontinuity in reported foreseeability at precisely the point where the cutoff for layoff occurred (i.e., at the point in seniority below which workers were laid off and above which they were not). Nevertheless, the retrospective and quasi-experimental nature of the study leaves some ambiguity about whether the findings were the result of self-protective motives. Because the Mark and Mellor (1991) investigation lacked the usual hindsight bias study's comparison to a no-outcome-information condition, it might be better characterised as a study of retrospective foreseeability judgements than as a study of hindsight bias.

Mark and Mellor's reasoning was that, when a person is directly affected by a negative event (such as a layoff from work), hindsight bias may be inhibited by a self-serving bias which has the adaptive function of preserving one's self-image (see, e.g., Blaine \& Crocker, 1993; Bradley, 1978; Mullen \& Riordan, 1988; Taylor \& Brown, 1988; Zuckerman, 1979; also see Mark \& Mellor, 1991, for additional details on the possible motivational bases of hindsight bias). That is, if an individual is directly affected by a negative event and acknowledges that the event was foreseeable, the person would likely feel increased responsibility for its occurrence. At the least, the person is likely to think counterfactually about things he or she should have done to have avoided the undesirable outcome or at least to have minimised its negative effects $^{1}$ (Macrae, 1992; Markman \& Tetlock, 2000; Roese \& Olson, 1996; Turley, Sanna, \& Reiter, 1995). This does not imply that hindsight bias would be attenuated by any negative outcome the person experiences. Rather, the outcome prob-

\footnotetext{
${ }^{1}$ The findings of Roese and Olson (1996) and Roese and Manier (1997), that counterfactual thinking increases the magnitude of hindsight bias, might seem to suggest the opposite effect, that is, that a search for alternative causes should lead to more hindsight when the person experiences a negative self-relevant outcome. However, Roese and Olson (1996) and Roese and Manier (1997) examined the effect of counterfactual thoughts that emphasised the predictability of the observed outcome. In contrast, we suggest that negative self-relevant outcomes stimulate counteractuals about alternative outcomes, and research shows that counterfactual reasoning that emphasises the explanation of alternative outcomes can reduce or eliminate hindsight bias (e.g., Arkes et al., 1988; Davies, 1992).
}

ably needs to be relevant in the sense of having feasible implications for the person's judgement, skills, culpability, and the like (as in the laid-off worker's decision to stay for years in the same job, while not increasing savings or training for other jobs).

Mark and Mellor focused on negative selfrelevant outcomes. The effect of positive selfrelevant outcomes is less clear. Given that positive self-relevant outcomes often stimulate selfenhancement (e.g., Taylor \& Brown, 1988), they may increase retrospective foreseeability judgements: "Of course I knew all along that this good thing would happen." However, the tendency to self-enhance appears to be less powerful than the tendency to self-protect (Agostinelli, Sherman, Presson, \& Chassin, 1992; Campbell, 1986; Goethals, 1986; Taylor, 1991; but cf. Miller \& Ross, 1975). This may be part of a more pervasive pattern whereby bad events are more powerful than good ones and, accordingly, self-protection is more powerful than self-enhancement (Baumeister, Bratslavsky, Finkenauer, \& Vohs, 2001). Thus, positive self-relevant events may be less likely than negative self-relevant events to influence foreseeability.

Research by Louie and her colleagues (Louie, 1999; Louie, Curren, \& Harich, 2000) addresses the question of positive versus negative self-relevant outcomes, while also extending Mark and Mellor's (1991) quasi-experimental methodology to controlled experiments. Louie's (1999, Study 1) participants read a case description of a company, decided whether they would like to buy its stock, and subsequently either learned the stock price had increased or decreased, or got no outcome information. Replicating Mark and Mellor (1991), there was no hindsight bias among people who experienced a negative self-relevant outcome (i.e., who decided to purchase the stock and its value declined, or who did not purchase and the value increased). That is, the retrospective foreseeability judgements of those who experienced a negative self-relevant outcome did not differ from those in the no-outcome-information condition. In contrast, those who experienced a positive self-relevant outcome showed hindsight bias. In addition, the pattern of attributions indicated that self-serving processes were operating. Louie (1999, Study 2) replicated these findings and showed that a manipulation intended to constrain self-serving biases eliminated the hindsight bias among those who experienced a positive selfrelevant outcome. 
Louie et al. (2000) extended research on selfserving biases and hindsight to a team setting. MBA students rated the likelihood of change in the market share of a target firm in a class simulation. They later learned of the target firm's performance and recalled their predictions. The target was either the firm run by the student's own team or a firm run by a team in another, parallel simulation (all teams competed for class grade). When students' own firm did badly they showed no hindsight, but students exhibited hindsight for the poor performance of another team. Conversely, students showed hindsight when their own firm did well, but did not exhibit hindsight for the good performance of another team.

The Louie (1999) and Louie et al. (2000) findings are consistent with Mark and Mellor's (1991) suggestion that self-relevance may moderate hindsight bias and, more generally, retrospective judgements of foreseeability. They also empirically extend the self-serving bias account to positive outcomes. The studies of Louie and her colleagues also compensate for the causal ambiguities that remain from Mark and Mellor's (1991) quasi-experimental investigation, while also using procedures that cleverly operationalise self-relevance (especially in the use of a real, graded classroom exercise in Louie et al., 2000). At the same time, important questions remain. One is whether outcomes that are positive and self-relevant actually influence judgements of foreseeability. In Louie's (1999) studies, those who experienced positive selfrelevant outcomes showed hindsight bias, relative to a no-outcome-information control group; however, no comparison was made to the retrospections of observers who saw the same outcome, but for whom it was low in self-relevance. It might be argued that such a comparison occurred in the Louie et al. (2000) study, where hindsight did not occur when students made judgements about another team's success. However, all teams were competing in terms of course grade, and another firm's actions highlight decisions that one's own firm did not take. Thus, another firm's success could have been interpreted as one's own team's failure. Therefore, findings for this group may simply replicate the finding that negative self-relevant findings attenuate hindsight bias.

In short, although the Mark and Mellor (1991) and Louie (1999; Louie et al., 2000) studies demonstrate the role of self-relevance in hindsight bias, they are not conclusive on the question of whether positive and negative outcomes have symmetrical effects. More generally, studies to date do not provide a clear disentangling of outcome valence and self-relevance which, furthermore, may vary as a function of one's perspective relative to the outcome. Louie et al. (2000) noted that the interpretation of an outcome may depend on one's perspective (e.g., they describe the case of a power company that defaulted on bonds, where the company's view of its ability to predict the default differed from that of investors who sued). Depending on one's perspective, an outcome may be directly self-relevant, indirectly self-relevant, or not at all relevant. Such differences in perspective may have important consequences for retrospective judgements about foreseeability.

In addition, in many contexts, comparative information is available simultaneously about one's own outcomes and those of others. Just as counterfactual reasoning that emphasises the explanation of alternative outcomes can reduce or eliminate hindsight bias (e.g., Arkes et al., 1988; Davies, 1992), it is possible that the simultaneous consideration of different parties' outcomes might make an outcome seem less foreseeable. In the Louie et al. (2000) research, however, participants were asked to consider only the target firm's performance.

We designed the present study, then, to test experimentally the effect of positive and negative outcomes, varying in self-relevance, on retrospective judgements of foreseeability. We predicted that for a negative, self-relevant outcome, participants would deny foreseeability (cf. Markman \& Tetlock, 2000, for similar predictions in the context of counterfactual thinking). Predictions for a positive, self-relevant outcome are more tenuous, but the findings of Louie (1999) and Louie et al. (2000) suggest that a positive outcome may increase, and at least should not decrease, foreseeability. To avoid ambiguity about the independent role of outcome valence and selfrelevance, we had observers, who did not directly experience the outcomes, also make judgements. In addition, because actual competitive settings often provide exposure to multiple outcomes simultaneously, we asked participants to make judgements about multiple outcomes. 


\section{METHOD}

\section{Overview and design}

In the context of a "stock market decision-making game", two players each "bought" a stock. A third individual was assigned to observe the game without actively participating. During the course of the game, one of the two players' stock either greatly decreased (negative outcome) or increased (positive outcome), while the other stock held a modest gain (neutral outcome). The extreme outcome should be most self-relevant for the player receiving it and least for the observer. All participants rated the foreseeability of the outcomes of both stocks.

Formally, the experiment employed a mixed factorial design, with player role (player 1, player 2 , or observer), recipient of extreme change (player 1 or player 2), and direction of extreme change (increase or decrease) as between-subject factors, and target of rating (player 1 or player 2) as a within-subject factor. However, the player 1player 2 distinction holds no substantive interest, and effects did not differ across these two roles. We therefore combined across the two player roles for analyses. Table 1 (see later) gives the simplified design.

\section{Participants}

Participants were 77 female and 46 male students enrolled in introductory psychology classes at Penn State University. Participants received extra course credit in exchange for participation.

\section{Procedure}

Participants, in groups of three, were recruited for an experimental game on decision making in a stock market setting. They were informed that the game would consist of two separate halves, and that the object of each half was to make as much money as possible by investing in one stock. Participants drew from a hat one of three cards labelled "Player 1", "Player 2", or "Observer". The experimenter explained that the two players would compete against each other in the first half, during which the observer would make judgements about both players' decisions and outcomes, and that in the second half the observer would also compete in the game (to increase the observer's motivation and attention). There was, in fact, no "second half". To increase motivation, participants were told that the winner of each half would be given tickets for a draw for $\$ 100$ in proportion to their "earnings". In addition, the observer was told that he or she would be entered in a separate $\$ 100$ draw for all observers. In actuality, all participants received an equal chance in two $\$ 100$ draws conducted at the end of data collection.

The experimenter explained that the first half of the game would last for three "trading weeks", with each trading week consisting of four "trading days" (Tuesday-Friday). The "days" and "weeks" of the stock-trading game all took place during a single 90-minute session. The available stocks were listed in the "College Street Journal", a one-page newsletter with a new edition for each trading day. Participants were told that the names of the stocks were fictional, but that their progress was charted from actual stocks. In reality, the temporal pattern of the stocks was controlled to manipulate the independent variables. The Journal, loosely modelled after the Wall Street Journal, contained fictional articles and information. Some articles were relevant to the stocks from which participants could choose, others were nonrelevant filler articles, and other features included the weather. The Journal also contained daily opening and closing trading prices for the eight stocks from which the players could choose. (Prior to beginning the game, the experimenter explained opening and closing prices and the calculation of profits or losses.)

All three participants received a packet of four College Street Journals, one for each day of the first trading week. After reading the Journals and observing a graph of the stocks' performance for the week, players invested $\$ 200$ by writing down their chosen stock and handing it to the experimenter. ${ }^{2}$ After answering a series of questions consistent with the cover story, participants received four more Journals for the second trading week. In addition to the daily opening and closing values of the eight stocks in the Journal,

\footnotetext{
${ }^{2}$ If both players made the same stock selection, they were informed that a penalty would be incurred if they invested in identical stocks. The penalty was that they would each get three fewer shares than their money could buy and the extra money would not be invested at any point in the game. If one person decided to change his or her choice, neither participant was penalised. Players rarely made the same stock selection, and in every instance one of the players changed his or her stock choice so that neither player was penalised. Deletion of the cases in which players initially made identical selections does not materially influence the results.
} 
for the second (and third) week the experimenter plotted the progress of the players' chosen stocks and total assets on a blackboard. During the second week, neither player's stock rose or fell in price to a great extent, but instead showed a modest upward trend (pilot testing had shown that this resulted in similar expectations for the two stocks' performance).

During the third trading week, one (randomly selected) player received either the extreme positive or negative outcome. The extreme increase or decrease in this stock's share price was given in the daily stock summary sections of the third week's set of College Street Journals, and represented just over a $10 \%$ rise or fall in the original investment over the period of a week. For example, in one case "Fitsu Computers" opened at $\$ 37.50$ per share on Day 1 of the third trading week and closed at $\$ 18.00$ per share on Day 4 , for a net loss of $\$ 19.50$ per share over the week. In addition, one of the journals for the third week also contained an article that explained why the extreme outcome occurred. In the instance of the extreme decline in "Fitsu Computers" price per share, an article explained that the stock declined sharply because the company's products were made outdated by a competitor. Two versions of the third week's Journal were prepared for each stock, and which version was distributed depended on the participants' stock choices and the condition. All other stocks, including that of the player who did not receive the extreme change, showed modest progress in the third week, similar to that of the first two weeks.

At the end of the third "trading week", participants answered a series of questions in a confidential questionnaire. This included a manipulation check, in which all participants rated, on a response scale ranging from (1) "increased greatly" to (9) "decreased greatly", the extent to which each stock's value changed in the last trading period. The dependent measure was a three-item "foreseeability scale". All participants rated, on nine-point scales, the extent to which each stock outcome was surprising ("I was surprised by the performance of this stock"), foreseeable ("I could foresee what this stock was going to do"), and obvious in foresight ("It was obvious after the first four-day trading period that this stock was going to perform as it did"). Coefficient alpha reliability was .77 , and the three items were averaged for analysis. Other questions assessed whether participants were suspicious of the cover story or had guessed the hypothesis in any way (no participants were suspicious). Participants were then fully debriefed. When the study was over, two $\$ 100$ draws were held.

\section{RESULTS}

\section{Manipulation check}

The manipulation check assessed the extent to which participants perceived each stock as increasing or decreasing in value. A 2 (extremity of outcome: "extreme" or "neutral") $\times 2$ (valence of the extreme outcome: positive or negative [i.e., a gain or a loss]) $\times 3$ (rater's perspective: recipient of the outcome, opponent, or observer) multivariate analysis of variance, with extremity as a within-subject factor, revealed the expected extremity $\times$ valence interaction, $F(1,117)=315.92, p<.01$. As expected, a Newman Keuls post-hoc test showed that extreme positive outcomes $(M=1.43)$ differed significantly from the extreme negative outcomes $(M=8.54)$, with the mean ratings indicating that these were seen, respectively, as having increased and decreased greatly. Also as expected, both extreme outcomes differed from the neutral outcomes. Ratings for the neutral condition were not affected by the valence of the opponent's extreme outcome. That is, a neutral outcome in the context of a "winning" opponent $(M=3.73)$ did not significantly differ from a neutral outcome in the context of a "losing" opponent $(M=2.84)$. In addition, no main effects or interactions were found that included the rater's perspective. ${ }^{3}$

\footnotetext{
${ }^{3}$ However, the interaction between extremity of outcome, valence, and rater perspective was marginally significant, $F(2,117)=2.71, p<.075$. The interaction appears to be driven by the tendency of winners (i.e., the recipients of the extreme positive outcome) to rate their opponent's neutral outcome as having increased less $(M=4.33)$ than did the recipients of neutral outcomes $(M=3.46)$ and observers $(M=3.50)$ (recall that the rating scale ranged from 1 , indicating the stock had increased greatly, to 9, decreased greatly). More importantly, ratings of neutral outcomes by their recipients did not depend on whether these outcomes occurred in the context of a winning $(M=3.46)$ or losing $(M=3.09)$ opponent. This absence of a contrast effect for the recipients of neutral outcomes suggests that these players did not see their opponent's outcome as relevant to themselves. That is, if the players who received a neutral outcome had seen their opponents' outcome as selfrelevant, this presumably would have led to a contrast effect in their ratings of their own neutral outcomes. Given that this did not occur, it seems most reasonable to expect that there should be no effect of the extreme outcome's valence on the foreseeability of neutral outcomes.
} 


\section{Effects on foreseeability}

Our primary prediction, drawing from the findings of Mark and Mellor and of Louie and her colleagues, was that participants who experienced an extreme negative outcome (the negative selfrelevant condition) would be more likely to deny the foreseeability of that outcome, relative to the opponents and observers who also observed that outcome. We were also interested in the somewhat more tenuous prediction that participants who experienced extreme positive outcomes might report higher foreseeability than their opponents and observers. Louie (1999; Louie et al., 2000) observed hindsight bias among those who experience a positive self-relevant outcome, but we are aware of no research that has compared such people with observers for whom the outcome is not self-relevant. For neutral outcomes, no differences in foreseeability ratings were predicted between the outcome recipient and the opponent and observer, because neutral outcomes were not expected to elicit self-protective or self-enhancing motives (see footnote 3 ).

To test these hypotheses, we conducted planned contrasts for each of the four types of outcomes (i.e., extreme negative, extreme positive, neutral in the context of a losing opponent, and neutral in the context of a winning opponent). The primary hypothesis test involved comparing the foreseeability of the outcome as rated by the player who experienced it with ratings of the same outcome by the opponent and the observer. For this contrast, weights of $2,-1$, and -1 were assigned to the outcome recipient, opponent, and observer, respectively. We also conducted a second planned contrast for each outcome, in which we compared the ratings of opponents with those of observers, to assess whether there was some degree of self-relevance that led opponents to judge an outcome differently from observers. For this contrast, weights of 0,1 , and -1 were assigned to the outcome recipient, opponent, and observer, respectively.

The first planned contrast was significant for extreme negative outcomes, $t(60)=2.57, p=.01, d$ $=0.66$. As shown in the first row of Table 1 , participants who received extreme negative outcomes were significantly less likely than their opponents or observers to indicate that this outcome was foreseeable. However, the opponent of the player who received an extreme negative outcome did not differ from the observer of this outcome. No significant differences were observed between the outcome recipient and other participants or between the opponent and the observer for extreme positive outcomes or for neutral outcomes. (Comparable results were observed when the recipient of an outcome was compared separately to the opponent and the observer.)

TABLE 1

Mean foreseeability ratings, Ns, (and SDs) for extreme and non-extreme outcomes, by rater

\begin{tabular}{|c|c|c|c|}
\hline \multirow[b]{2}{*}{ Outcome rated } & \multicolumn{3}{|c|}{ Rater of outcome } \\
\hline & Outcome recipient & Opponent & Observer \\
\hline \multicolumn{4}{|l|}{ Extreme outcome } \\
\hline Negative $^{\mathrm{a}}$ & $2.36(1.43)$ & $3.32(1.80)$ & $3.88(2.15)$ \\
\hline $\mathrm{n}$ & 22 & 19 & 22 \\
\hline Positive $^{\mathrm{b}}$ & $4.73(1.22)$ & $4.02(2.23)$ & $4.80(1.63)$ \\
\hline $\mathrm{n}$ & 22 & 18 & 20 \\
\hline \multicolumn{4}{|l|}{ Neutral outcome } \\
\hline Losing opponent ${ }^{\mathrm{b}}$ & $6.00(1.09)$ & $5.83(1.90)$ & $6.32(1.47)$ \\
\hline $\mathrm{n}$ & 19 & 22 & 22 \\
\hline Winning opponent ${ }^{\mathrm{b}}$ & $5.43(1.81)$ & $4.85(1.41)$ & $4.97(1.32)$ \\
\hline $\mathrm{n}$ & 18 & 22 & 20 \\
\hline
\end{tabular}

${ }^{a}$ In this row, the outcome recipient significantly differs from the others (i.e., opponent and observer) at $p<.05$ (i.e., Contrast 1 was significant).

${ }^{\mathrm{b}}$ In this row, neither planned contrast approached significance.

Higher means indicate greater perceived foreseeability of the outcome. 


\section{DISCUSSION}

\section{The effect of self-relevant outcomes, negative and positive}

Consistent with Mark and Mellor's (1991) findings and with the findings of Louie (1999) and Louie et al. (2000) for negative self-relevant outcomes, we found that when people experience outcomes that are negative and self-relevant, they see these outcomes as less foreseeable than do others observing the same outcome. In particular, when one player's stock dropped precipitously, the person who had selected that stock saw the drop as significantly less foreseeable than did the opponent or the observer. It appears that self-protective biases can operate to defend against the threat to the self-concept that would otherwise occur after experiencing negatively valenced outcomes which could have negative implications for one's sense of self-in other words, after making a predictably bad decision (Blaine \& Crocker, 1993; Mullen \& Riordan, 1988; Taylor \& Brown, 1988; Zuckerman, 1979). ${ }^{4}$ The present findings extend past research by experimentally comparing those who received negative self-relevant outcomes with observers and opponents who received the same outcome information but for whom the outcome was not self-relevant.

Despite the present and past evidence that negative, self-relevant outcomes attenuate foreseeability, there may be some circumstances in which negative self-relevant outcomes would increase retrospective foreseeability and hindsight bias. Holding the minority opinion about a group decision may be one such circumstance. For example, if a married couple disagreed about whether or not to invest in a stock, and one prevailed on the other to buy, the dissenting partner may experience heightened hindsight bias if the stock declines precipitously.

In contrast to negative outcomes, no effect of self-relevance was observed for positive outcomes. Players who experienced a dramatic rise in

\footnotetext{
${ }^{4}$ The attributional findings from Louie (1999) support this classic motivational form of self-serving bias effect, as does the attenuation of hindsight in Louie et al. (2000) in response to a manipulation designed to inhibit self-serving biases. At the same time, the findings for negative self-relevant outcomes could have arisen at least in part because of related cognitive processes that are likely to be initiated by such outcomes. See Mark and Mellor (1991) for a summary of various cognitive processes that might also contribute to a self-serving pattern of responses.
}

their stock's value did not see this outcome as more (or less) foreseeable than did their opponents or the observer. This may seem inconsistent with Louie (1999) and Louie et al's. (2000) finding of hindsight bias among those who received positive self-relevant outcomes. In fact, however, there may be no inconsistency. Although Louie's studies demonstrated hindsight among those who received positive outcomes, relative to a no-outcome-information condition, they did not examine whether the magnitude of their hindsight bias was greater than for people who knew the outcome but for whom it was not relevant. Adding to the findings of Louie (1999) and Louie et al. (2000), the current results suggest that positive self-relevant outcomes do not significantly increase or decrease retrospective foreseeability judgements, relative to those who receive outcome information without self-relevance. This pattern of asymmetrical results is consistent with research in a number of areas showing larger responses to negative information and events than to positive ones (Baumeister et al., 2001).

Although we found no impact of positive selfrelevant outcomes on hindsight in the present research, it would be premature to conclude that only negative self-relevant outcomes influence perceived foreseeability (and, by extension, hindsight bias). For example, positive selfrelevant outcomes might increase hindsight bias under circumstances in which self-enhancing motivations are intensified, such as when the person's self-esteem had previously been threatened. In such a case, self-enhancing motives may be increased, and claiming inflated foresight of a positive outcome would serve as a form of selfaffirmation (Steele, 1988). In addition, positive outcomes that are more intensely self-relevant than those manipulated in the present research might themselves stimulate self-enhancement.

\section{Self-relevance and self-serving processes}

The high self-relevant conditions in the present research may have been less self-relevant than their counterparts in previous studies. Certainly in relation to being laid off from work, and perhaps relative to a graded assignment in an MBA marketing course (Louie et al., 2000), there may be less self-relevance for psychology undergraduates who receive an extreme outcome in a stock market game. One possible implication, just noted, is 
that more intensely self-relevant outcomes might elicit self-enhancement for positive outcomes ("Of course, I expected all along that things would turn out so well"), as well as self-protection for negative outcomes. More generally, the question might be raised as to whether the observed effects are truly due to self-serving biases or instead are the result of self-presentation (e.g., Schlenker, 1980).

There are several reasons we believe the findings are consistent with self-serving bias rather than self-presentation. First, our results for negative outcomes converge with those of Mark and Mellor (1991), Louie (1999), Louie et al. (2000), and Renner (2003, this issue, for the delayed measures), whose findings are not all easily accounted for by self-presentation. Second, Louie et al. (2000) explicitly presented attributional and experimental evidence designed to support a selfserving bias account, and Renner (2003-this issue) presents evidence that implicates perceived threat as having a mediating role, consistent with the self-serving bias interpretation. These findings provide evidence implicating self-serving rather than self-presentational processes. Third, the procedure we used, with the implication for lottery tickets and the competitive task, clearly engaged our participants, who generally appeared to care about the outcome. Facial expressions, cheers or moans, and verbal exclamations often accompanied the extreme outcomes. Fourth, the data collection procedures indicated that responses were anonymous. No personal identifiers were associated with the responses, nor were there any other apparent cues to elicit self-presentation. Although these procedures do not completely rule out the possibility that participants were to some extent concerned about self-presentation, the convergence of evidence across studies leads us to endorse a self-serving bias interpretation.

\section{Retrospective judgements of foreseeability versus hindsight bias}

The present research examined the effect of outcome valence and self-relevance on retrospective judgements of foreseeability. We did not collect measures of judgements in foresight, nor did we include a no-outcome-information control condition, as is standard in research on hindsight bias. Nevertheless, the findings, at least for negative self-relevant outcomes, converge with other research (e.g., Louie, 1999; Louie et al., 2000) that included the traditional hindsight bias comparisons.

We argue that potential benefits may accrue if research on retrospections about foreseeability breaks out of a strict hindsight bias research mould. Attention to hindsight bias has generated a rich array of empirical and conceptual developments (as this Special Issue of Memory illustrates). At the same time, any theoretical perspective or research tradition can also act as a set of blinders, diverting attention away from some questions while focusing attention on others (Greenwald, Pratkanis, Leippe, \& Baumgardner, 1986). From this perspective, it may not have been coincidental that the Mark and Mellor (1991) investigation of self-serving biases, which Renner (2003-this issue, p. 457) characterises as the first hindsight study in a "highly self-relevant and consequential setting", occurred in a real-world, quasi-experimental investigation that did not parallel conventional hindsight bias designs. As another example, without broadening the field's focus to perceived foreseeability in general, we may fail to learn when it is that people spontaneously estimate the likelihood of an outcome in foresight (cf. Beach, 1993; Wong \& Weiner, 1981).

In addition to serving as blinders on investigators' attention, research traditions often bring practical constraints as well. For instance, the present research included an observer who had outcome information but for whom the outcome lacked self-relevance, as well as participants for whom each outcome was self-relevant. Obviously, it would be possible (and, indeed, informative) to include such conditions in a traditional hindsight bias study that also manipulated outcome knowledge. However, there are practical limits on study size, especially in the relatively complex settings needed to observe motivational influences such as the influence of self-protection. And there could be pragmatic challenges of manipulating all these variables successfully in a single study. For example, a self-relevance manipulation may not be equally potent for those in a no-outcome information control condition as for those in an outcome-information condition.

Such constraints may hinder progress unless research on hindsight bias is diversified to study, more generally, the psychology of retrospective judgements of foreseeability. Indeed, a case can be made that arbitrary methodological traditions may have helped keep researchers from fully considering the role of self-serving biases until recently. The traditional paradigms used to 
investigate hindsight bias do not allow a meaningful assessment of the impact of self-relevance. Hindsight bias research typically involves participants receiving feedback about their performance on test items (e.g., Hoch \& Loewenstein, 1989), or making judgements about the outcomes of scenarios (e.g., Fischhoff, 1975; Wasserman, Lempert, \& Hastie, 1991) or about the performance of some paper-and-pencil other (e.g., Schkade \& Kilbourne, 1991) or product (e.g., Mazursky \& Ofir, 1990). To test hypotheses about the role of self-relevance, or to have a serendipitous finding that suggests self-serving processes, it is necessary to use a procedure that allows participants to be exposed to positively or negatively valenced outcomes that vary in self-relevance (Renner, 2003this issue). It has often been observed that methodological choices can restrict the development of knowledge, and this may be another case in point.

In addition, although the term hindsight bias may be well established, the field is moving away from a conceptualisation of the phenomenon as a bias and towards a view of hindsight as a byproduct of a generally adaptive learning process (e.g., Hoch \& Loewenstein, 1989; Hoffrage et al., 2000; Roese \& Olson, 1996). There appear to be important intersections among hindsight bias/ foreseeability, counterfactual thinking, causal attributions, the overconfidence effect, and other phenomena (e.g., Hertwig, Gigerenzer, \& Hoffrage, 1997; Lipe, 1991; Roese \& Olson, 1996; Sherman \& McConnell, 1995; Wasserman et al., 1991). Viewed from this broader perspective, findings about the relative degree of retrospective foreseeability can be quite informative, depending on the research question, even without the usual comparisons that allow an estimate of the degree of hindsight "bias".

\section{Self-related concerns and recent work on hindsight bias}

The present results may have implications for other research questions, including the ongoing debate about relationship between surprise and hindsight bias (e.g., Arkes et al., 1988; Mark \& Mellor, 1994; Mazursky \& Ofir, 1990; Ofir \& Mazursky, 1997; Pezzo, 2003-this issue; Schkade \& Kilbourne, 1991; Verplanken \& Pieters, 1988). In particular, future research might fruitfully examine whether the relationship between surprise and hindsight is moderated by outcome valence and self-relevance. When surprise occurs in the context of a negative self-relevant outcome, hindsight bias may be attenuated by self-protective processes. On the other hand, when an outcome that would a priori be classified as surprising takes place in the context of a positive self-relevant outcome, the findings of Louie et al. (2000) and the present research suggest that the hindsight bias will not be attenuated. Pezzo (2003-this issue) also raises a potentially important distinction between culpability and self-relevance, and it may well be that negative self-relevant outcomes will attenuate hindsight, and therefore moderate the relationship between hindsight and surprise, only when the person feels some sense of personal responsibility for the outcome (culpability). This distinction may explain why Tykocinsky (2001) found that people saw a negative event as more likely in retrospect-they probably did not see themselves as culpable. For instance, the Israeli college student participants in Tykocinsky's Study 2 probably did not see themselves as personally responsible for the defeat of their preferred candidate for Prime Minister. Also see both Pezzo (2003-this issue) and Renner (2003-this issue) for suggestions that the relationship between surprise and hindsight bias may change over time.

Work on self-relevance might also fruitfully be integrated with other recent work on the processes underlying hindsight. Take as an example Hoffrage et al.'s (2000) RAFT (Reconstruction After Feedback with Take the Best) model. This model makes three general assumptions about the "recollection process (at Time 3): First, if the original choice (made at Time 1) cannot be retrieved from memory, it will be reconstructed by rejudging the problem. Second, the reconstruction involves the attempt to recall the knowledge on which the original choice was based. Third, the outcome information received (at Time 2) is used to update old knowledge, in particular knowledge that was elusive and missing at Time 1. In conjunction, these assumptions suffice to explain the occurrence of hindsight bias." (Hertwig, Fanselow, \& Hoffrage, 2003-this issue, p. 360). Research on self-relevance might be able to complement the RAFT model (or any other model of hindsight). The reconstruction process may be influenced, not only by recall of the cues that were involved in the original choice and by the (updated) cue values, but also by self-serving considerations in the case of self-relevant outcomes. In essence, self-serving processes involve questions of the form, "How likely is it that I would have selected a stock if it 
was obvious that it would decline precipitously in value?" It is unclear precisely when self-serving processes are integrated with the results of the reconstruction identified by the RAFT model. As the present research suggests, however, the processes generated by a negative self-relevant outcome can counteract the knowledge updating that would otherwise occur as a result of outcome knowledge. In short, self-serving processes may need to be taken into consideration to obtain a comprehensive understanding of hindsight.

\section{REFERENCES}

Agostinelli, G., Sherman, S. J., Presson, C. C., \& Chassin, L. (1992). Self-protection and selfenhancement biases in estimates of population prevalence. Personality and Social Psychology Bulletin, 18, 631-642.

Arkes, H. R., Faust, D., Guilmette, T. J., \& Hart, K. (1988). Eliminating the hindsight bias. Journal of Applied Psychology, 73, 305-307.

Arkes, H. R., Wortmann, R. L., Saville, P. D., \& Harkness, A. R. (1981). Hindsight bias among physicians weighting the likelihood of diagnoses. Journal of Applied Psychology, 66, 252-254.

Baumeister, R. F., Bratslavsky, E., Finkenauer, C., \& Vohs, K. D. (2001). Bad is stronger than good. Review of General Psychology, 5, 323-370.

Beach, L. R. (1993). Broadening the definition of decision making: The role of prechoice screening of options. Psychological Science, 4, 215-220.

Blaine, B., \& Crocker, J. (1993). Self-esteem and selfserving biases in reactions to positive and negative events: An integrative review. In R. F. Baumeister (Ed.), Self-esteem: The puzzle of low self-regard (pp. 55-85). New York: Plenum Press.

Bradley, G. W. (1978). Self-serving biases in the attribution process: A reexamination of the fact or fiction question. Journal of Personality and Social Psychology, 36, 56-71.

Brown, J. D. (1986). Evaluations of self and others: Selfenhancement biases in social judgments. Social Cognition, 4, 353-376.

Campbell, J. D. (1986). Similarity and uniqueness: The effects of attribute type, relevance, and individual differences in self-esteem and depression. Journal of Personality and Social Psychology, 50, 281-294.

Christensen-Szalanski, J. J. J., \& Willham, C. F. (1991). The hindsight bias: A meta-analysis. Organizational Behavior and Human Decision Processes, 48, 147-168.

Cook, T. D., \& Campbell, D. T. (1979). Quasi-experimentation. Chicago: Rand McNally.

Davies, M. F. (1992). Field dependence and hindsight bias: Cognitive restructuring and the generation of reasons. Journal of Research in Personality, 26, $58-74$.

Dunning, D., Leuenberger, A., \& Sherman, D. A. (1995). A new look at motivated inference: Are self serving theories of success a product of motivational forces? Journal of Personality and Social Psychology, 69, 58-68.

Fischhoff, B. (1975). Hindsight $\neq$ foresight: The effect of outcome knowledge on judgment under uncertainty. Journal of Experimental Psychology: Human Perception and Performance, 1, 288-299.

Fischhoff, B. (1982). For those condemned to study the past: Heuristics and biases in hindsight. In D. Kahneman, P. Slovic, \& A. Tversky (Eds.) Judgment under uncertainty: Heuristics and biases (pp. 335-351). New York: Cambridge University Press.

Goethals, G. R. (1986). Fabricating and ignoring social reality: Self-serving estimates of consensus. In J. Olson, C. P. Herman, \& M. P. Zanna (Eds.), Relative deprivation and social comparison: The Ontario Symposium on Social Cognition: IV (pp. 135-157). Hillsdale, NJ: Lawrence Erlbaum Associates Inc.

Greenwald, A. G. (1980). The totalitarian ego: Fabrication and revision of personal history. American Psychologist, 35, 603-618.

Greenwald, A. G., Pratkanis, A. R., Leippe, M. R., \& Baumgardner, M. H. (1986). Under what conditions does theory obstruct research progress? Psychological Bulletin, 93, 216-229.

Hawkins, S. A., \& Hastie, R. (1990). Hindsight: Biased judgments of past events after the outcomes are known. Psychological Bulletin, 107, 311-327.

Hertwig, R., Fanselow, C., \& Hoffrage, U. (2003). Hindsight bias: How knowledge and heuristics affect our reconstruction of the past. Memory, 11, 357-377.

Hertwig, R., Gigerenzer, G., \& Hoffrage, U. (1997). The reiteration effect in hindsight bias. Psychological Review, 104, 194-202.

Hoch, S. J., \& Loewenstein, G. F. (1989). Outcome feedback: Hindsight and information. Journal of Experimental Psychology: Learning, Memory and Cognition, 15, 605-619.

Hoffrage, U., Hertwig, R., \& Gigerenzer, G. (2000). Hindsight bias: A by-product of knowledge updating? Journal of Experimental Psychology: Learning, Memory, and Cognition, 26, 566-581.

Kunda, Z. (1987). Motivated inference: Self-serving generation and evaluation of causal theories. Journal of Personality and Social Psychology, 53, 636-647.

Lipe, M. G. (1991). Counterfactual reasoning as a framework for attribution theories. Psychological Bulletin, 109, 456-471.

Louie, T. A. (1999). Decision makers' hindsight bias after receiving favorable and unfavorable feedback. Journal of Applied Psychology, 84, 29-41.

Louie, T. A., Curren, M. T., \& Harich, K. R. (2000). "I knew we would win": Hindsight bias for favorable and unfavorable team decision outcomes. Journal of Applied Psychology, 85, 264-272.

Macrae, C. N. (1992). A tale of two curries: Counterfactual thinking and accident-related judgments. Personality and Social Psychology Bulletin, 18, 84-87.

Mark, M. M., \& Mellor, S. (1991). Effect of selfrelevance of an event on hindsight bias: The foreseeability of a layoff. Journal of Applied Psychology, $76,569-577$. 
Mark, M. M., \& Mellor, S. (1994). "We don't expect it happened": On Mazursky and Ofir's purported reversal of the hindsight bias. Organizational Behavior and Human Decision Processes, 57, 170-181.

Markman, K. D., \& Tetlock, P. E. (2000). "I couldn't have known": Accountability, foreseeability and counterfactual denials of responsibility. British Journal of Social Psychology, 39, 313-325.

Mazursky, D., \& Ofir, C. (1990). "I could never have expected it to happen": The reversal of the hindsight bias. Organizational Behavior and Human Decision Processes, 46, 20-33.

Miller, D. T., \& Ross, M. (1975). Self-serving biases in attribution of causality: Fact or fiction? Psychological Bulletin, 82, 213-225.

Mullen, B., \& Riordan, C. A. (1988). Self-serving attributions for performance in naturalistic settings: A meta-analytic review. Journal of Applied Social Psychology, 18, 3-22.

Ofir, C., \& Mazursky, D. (1997). Does a surprising outcome reinforce or reverse the hindsight bias? Organization Behavior and Human Decision Processes, 69, 51-57.

Pezzo, M. V. (2003). Surprise, defence, or making sense: What removes the hindsight bias? Memory, 11, 421441.

Renner, B. (2003). Hindsight bias after receiving selfrelevant health risk information: A motivational perspective. Memory, 11, 455-472.

Roese, N. J., \& Manier, S. D. (1997). Perceptions of purple: Counterfactual and hindsight judgments at Northwestern Wildcats football games. Personality and Social Psychology Bulletin, 23, 1245-1253.

Roese, N. J., \& Olson, J. M. (1996). Counterfactuals, causal attributions, and the hindsight bias: A conceptual integration. Journal of Experimental Social Psychology, 32, 197-227.

Schkade, D. A., \& Kilbourne, L. M. (1991). Expectation-outcome consistency and hindsight bias. Organizational Behavior and Human Decision Processes, 49, 105-123.

Schlenker, B. R. (1980). Impression management: The self-concept, social identity, and interpersonal relations. Belmont, CA: Brooks/Cole.
Schwarz, S., \& Stahlberg, D. (2003). Strength of hindsight bias as a consequence of meta-cognitions. Memory, 11, 395-410.

Sherman, S. J., \& McConnell, A. R. (1995). Dysfunctional implications of counterfactual thinking: When alternatives to reality fail us. In N. J. Roese \& J. M. Olson (Eds.), What might have been: The social psychology of counterfactual thinking (pp. 199-232). Mahwah, NJ: Lawrence Erlbaum Associates Inc.

Steele, C. M. (1988). The psychology of self-affirmation: Sustaining the integrity of the self. In L. Berkowitz (Ed.), Advances in experimental social psychology (Vol. 21, pp. 261-302). Orlando, FL: Academic.

Taylor, S. E. (1991). Asymmetrical effects of positive and negative events: The mobilization-minimization hypothesis. Psychological Bulletin, 110, 67-85.

Taylor, S. E., \& Brown, J. D. (1988). Illusion and wellbeing: A social psychological perspective on mental health. Psychological Bulletin, 103, 193-210.

Turley, K. J., Sanna, L. J., \& Reiter, R. L., (1995). Counterfactual thinking and perceptions of rape. Basic and Applied Social Psychology, 17, 285-303.

Tykocinski, R. E. (2001). I never had a chance: Using hindsight tactics to mitigate disappointments. Personality and Social Psychology Bulletin, 27, 376-382.

Verplanken, B., \& Pieters, R. G. (1988). Individual differences in reverse hindsight bias: I never thought something like Chernobyl would happen. Did I? Journal of Behavioral Decision Making, 1, 131-147.

Wasserman, D., Lempert, R. O., \& Hastie, R. (1991) Hindsight and causality. Personality and Social Psychology Bulletin, 17, 30-35.

Wong, P. T. P., \& Weiner, B. (1981). When people ask "why" questions and the heuristics of attributional search. Journal of Personality and Social Psychology, 40, 650-663.

Wood, J. V., Taylor, S. E., \& Lichtman, R. R. (1985). Social comparison in adjustment to breast cancer. Journal of Personality and Social Psychology, 49, 1169-1183.

Zuckerman, M. (1979). Attribution of success and failure revisited, or: The motivational bias is alive and well in attribution theory. Journal of Personality, 47, 245-287. 
Copyright $\odot 2003$ EBSCO Publishing 